\title{
Facility arrangements and the environmental performance of disposable and reusable cups
}

\author{
José Potting 1,2,3 • Eugenie van der Harst ${ }^{2}$
}

Received: 5 November 2014 / Accepted: 2 June 2015 /Published online: 20 June 2015

(C) The Author(s) 2015. This article is published with open access at Springerlink.com

\begin{abstract}
Purpose This paper integrates two complementary life cycle assessment (LCA) studies with the aim to advice facility managers on the sustainable use of cups, either disposable or reusable. Study 1 compares three disposable cups, i.e., made from fossil-based polystyrene (PS), biobased and compostable plastic (polylactic acid; PLA) and paper lined with PLA (biopaper). Study 2 compares the disposable PS cup with reusable cups that are handwashed or dishwashed.

Methods Existing LCA studies show inconsistent and sometimes conflicting results, due to differences in used data and modeling choices. The comparison of disposable cups, study 1, deliberately applied multiple inventory data sets for relevant life cycle processes and multiple crediting principles for recycling. Included waste treatment options in study 1 were incineration, recycling, composting, and anaerobic digestion (last two not for the disposable PS cup). The PS cup is next compared with handwashed and dishwashed reusable cups (study 2). LCAs for the reusable cups use single data sets, and explore the influence of an increasing number of reuses. Cup LCA results were only compared within, and not across
\end{abstract}

Responsible editor: Hans-Jürgen Garvens

José Potting

josepha.potting@abe.kth.se

1 PBL Netherlands Environmental Assessment Agency, Antonie van Leeuwenhoeklaan 9, 3721 MA Bilthoven, The Netherlands

2 Environmental Systems Analysis Group, Wageningen University, Droevendaalste steeg 3, 6708 PB Wageningen, The Netherlands

3 Environmental Strategies Research (fms) division, KTH Royal Institute of Technology, Drottning Kristinas väg 30, 100 44 Stockholm, Sweden impact categories. All data relate to cups used with hot beverage vending machines in Dutch office settings.

Results and discussion Impact results for each disposable cup show large and overlapping spreads. This prevents identifying a preferable disposable cup material, though still allows cautious preferences about waste treatment processes. Composting biocups is less good than other waste treatment processes. Average impact results for anaerobic digestion perform in almost all impact categories better than incineration for the PLA cup. Average impact results for recycling perform slightly better than incinerating for both biocups, but not for the PS cup. This comparison is affected, however, by the relatively large credits for avoided Dutch electricity production. Impact results for reusable cups do not perform better than disposable cups if both are used once. Impact results for the reusable cups contain large uncertainty due to widely varying user behavior.

Conclusions Overall results do not allow any preference for one of the disposable cups or for disposable versus reusable cups. All cups can be used for more than one consumption. This gives a considerable environmental gain for the second and third hot beverage consumption with all cups. Facility managers can encourage a second or third serving with the same cup by financial incentives, only putting on dishwashers around noon and after working time, and/or consumer awareness activities.

Keywords Disposable and reusable cups · Environmental LCA $\cdot$ Facility arrangements $\cdot$ Multiple inventory data sets and modeling choices $\cdot$ Scenarios

\section{Introduction}

Disposable cups were introduced in the first half of the last century and have meanwhile penetrated all sectors in society. Official numbers are not publicly available, but Wikiversity 
(2014) claims a worldwide use of 300 billion disposable cups per year (i.e., 300E9 disposable cups/year). Many restaurants and kiosks sell beverages in disposable cups for on-the-go consumption (e.g., by commuters, shopping public, or beach visitors). Disposable cups are also typically employed where absence of cleaning facilities and large numbers of customers in short time intervals make reusable cup service practically impossible. This is not only at stake for large public events like festivals and manifestations, but also in medium and large organizations as schools and universities with peak consumption during breaks. Disposable cups are also increasingly used in office-type organizations, typically in combination with vending machines, to save time and money and to streamline their hot beverage facilities (Potting and Van der Harst 2014; Heuvelmans and Ploum 2010).

Whereas disposable cups were introduced in the first half of the last century for their contribution to public health, i.e., for replacing the unhealthy "common drinking cups" near public drinking water facilities (Potting and Van der Harst 2014), they became, in the second half of the previous century, increasingly associated with an unnecessary use of scarce resources and a superfluous production of waste (Reinink et al. 1991; Heuvelmans and Ploum 2010). The debate about disposable cups already goes on for decennia, though the proposed solutions have slightly shifted over the years, also given changing facility arrangements for providing hot beverages in particular. In the recent past, when organizations typically had restaurant facilities or a room-to-room-service by a "coffee-lady," reusable cups were often put forward as the obvious alternative for disposable cups (Reinink et al. 1991). Restaurant facilities and "coffeeladies" will nowadays not be easily found anymore, however, as many organizations presently make use of vending machines for providing hot and cold beverages. Such vending machines typically go along with disposable cups made from fossil-based plastic, e.g., polystyrene (PS) or polypropylene (PP), or from paper lined with fossil plastic or wax. An alternative for the conventional disposable cups has recently become available with the introduction of the so-called biocups. Disposable biocups are made from materials that are renewable and have the compostability label (EN 13432). The most common disposable bioplastic cups are made from polylactic acid (PLA), typically produced from corn (NatureWorks LLC 2011). Disposable biopaper cups are obviously from paper, but lined with bioplastic instead of fossil-based plastic (Van der Harst et al. 2014).

Their renewable and compostable characteristics make biocups in the eyes of many stakeholders more environmental friendly than the conventional disposable cups from fossilbased plastic or paper lined with fossil-based plastic (Jager 2008). Several restaurant facilities and catering services, or organizations buying these facilities or services, therefore presently consider a transition from conventional disposable cups to disposable biocups. Wageningen University and Research (Wageningen UR) in the Netherlands, who up to recently used disposable PS cups for all their hot beverage vending machines, also considered replacing these disposable PS cups by disposable biocups of PLA or biopaper. In addition, they also thought about replacing incinerating the disposed cups, as was done then, by a more environmentally beneficial waste treatment process. Wageningen UR therefore started an internal project investigating the pros and cons of the disposable biocups compared to the conventional disposable PS cup, including different waste treatment options.

The internal research project of Wageningen UR involved a series of comprehensive studies into the environmental, economic as well as social aspects of a possible transition in their own organization from disposable PS cups to disposable biocups and/or a transition from incineration to another waste treatment process. A survey under employees and students of Wageningen UR turned out that over half of the office building inhabitants for environmental reasons is using an own reusable cup (Heuvelmans and Ploum 2010). Reusable cups were therefore added to the comparison with the conventional disposable PS cup. It goes too far to describe the whole research project here (see therefore Potting 2013; in Dutch), but this paper presents the environmental comparisons of the disposable PS cup with the disposable PLA and biopaper cup (study 1), and with a reusable cup that is handwashed or dishwashed (study 2). The environmental comparisons in both studies are based in life cycle assessment (LCA). In the comparative LCA study of the disposable cups (study 1), four waste treatment options are included, i.e., incineration, recycling, composting, and anaerobic digestion (the latter two only for the disposable biocups).

Environmental comparison of different types of disposable cups and disposable with reusable cups is not new (e.g., Franklin Associates 2006, 2009, 2011; Vercalsteren et al. 2006; Ligthart and Ansems 2007; PE Pladerer et al. 2008; Uihlein et al. 2008; Americas 2009; Häkkinen and Vares 2010). Existing LCA studies, however, show inconsistent and sometimes conflicting results for comparisons of different disposable cups (Van der Harst and Potting 2013) and also for comparisons between disposable and reusable cups. This can be traced back for disposable cups to differences across LCA studies in data used and modeling choices made (Van der Harst and Potting 2013). The LCA study comparing disposable cups, i.e., study 1 , therefore deliberately applied multiple inventory data sets for all relevant life cycle processes and multiple crediting principles for recycling (a modeling choice). LCA study 2 took a screening approach in comparing the disposable PS cup with handwashed and dishwashed reusable cups. The second study thus refrained from using multiple inventory data sets and modeling choices for the reusable cup LCAs, but explored the influence of multiple times using them. Both studies are complementary and integrating their results enables making suggestions for environmentally beneficial facility arrangements.

The purpose of this paper is to advice facility managers on the sustainable use of cups, either disposable or reusable, 
based on the two reported LCA studies. Furthermore, the paper communicates some main learnings from the Wageningen UR project, and in particular, methodological learnings from study 1 in this paper (Van der Harst and Potting 2014; Van der Harst et al. 2014).

\section{Methods and means}

As mentioned in Section 1, this paper reports and integrates two comparative LCA studies that complement each other. Study 1 focuses on comparing three disposable cups (i.e., from PS, PLA, and biopaper) in combination with four waste treatment options (i.e., incineration, recycling, composting, and anaerobic digestion). Study 2 emphasizes on comparing the disposable PS cup with a reusable cup that is handwashed or dishwashed. Both studies took the same LCA approach, except for the inventory phase. Study 1 deliberately applied multiple inventory data sets for the most relevant processes and crediting principles for recycling (Van der Harst and Potting 2014; Van der Harst et al. 2014), whereas study 2 refrained from this and took a screening approach in inventory analysis for the reusable cups (Potting 2013; Potting and Van der Harst 2014). Inventory analysis for study 1 is summarized in Section 2.1 , because details have already been published in peerreviewed journals (Van der Harst and Potting 2014; Van der Harst et al. 2014). Study 2 has not yet been scientifically published and its inventory analysis is therefore described in more detail in Section 2.2. Also, original in this paper is the synthesis of results of both studies for discussing their meaning for facility arrangements (Section 3.5). An earlier version of this paper has been platform presented at the LCA Food 2014 conference in San Francisco (USA) (Potting and Van der Harst 2014).

Both LCA studies, as mentioned, took the same methodological approach in the other LCA phases than inventory analysis (Potting and van der Harst 2014; Potting 2013; Van der Harst and Potting 2014; Van der Harst et al. 2014):

Functional unit and reference flows Both LCA studies used the same functional unit of facilitating the serving of one hot beverage from a vending machine as frequently used in the Netherlands in large organizations nowadays. This functional unit puts constraints on the disposable cups, as most hot beverage vending machines in the Netherlands use disposable cups with a volume of $180 \mathrm{ml}$. Vending machines with automatic cup supply typically use disposable PS cups and are expected to also function well with disposable PLA cups for hot beverages (which are yet not widely used, and to our knowledge, also not commercially produced). Disposable paper cups tend in practice to disrupt vending machines with automatic cup supply (Heuvelmans and Ploum 2010). Organizations selling and leasing vending machines with automatic cup supply, however, advertise these in combination with disposable paper cups.
Disposable paper cups are obviously no problem for vending machines, with cups next to them, where the user needs to place a cup under the hot beverage outlet. The latter also allows the use of reusable cups. The weights of the analyzed disposable cups were $4.2 \mathrm{~g}$ for the PS and PLA ones and $5.6 \mathrm{~g}$ for the biopaper one (see Table 1). The reusable cups were taken to be $370 \mathrm{~g}$ and assumed to be used 1750 times before being sent to the incinerator.

Impact assessment Results from the inventory phase were translated into environmental impact by means of the CML Baseline 2001 methodology (Guinée et al. 2002), supplemented with the cumulated energy demand (CED) from Frischknecht et al. (2003). Many LCA comparisons of biobased versus fossil-based products focus on global warming potential (GWP) and non-renewable energy use (NREU). Several reviews have criticized these limited LCA studies and recommend encompassing a wider range of impact categories (e.g., Von Blottnitz and Curran 2007; Weiss et al. 2012). GWP, NREU, and abiotic resource depletion (ADP) are strongly correlated and sensitive for the environmental merits from non-renewable resources. Since these impact categories would largely provide similar information, we used CED instead of NREU. CED includes all energy sources (e.g., fossil, nuclear, renewable). This gives important additional information, namely about the main energy demanding processes in a product life cycle as basis for where energy demand can be reduced most effectively (either nonrenewable or renewable).

Both comparisons thus covered altogether 11 environmental impact categories (see Table 2). Impact results were not normalized and neither weighted. ISO 14044 (2006) rejects normalization and weighting in comparative LCAs which results are to be disclosed to the public. In line with this, cup comparisons were made only within each impact category, and not across impact categories.

Interpretation The results for the in-depth LCA study of the disposable cups were carefully evaluated against the background of the methodological approach used, quality of data obtained, and relevance of the results. The screening LCAs of the handwashed and dishwashed reusable cups provided indicative impact results that were compared with average impact results of the in-depth LCA for the disposable PS cup. The results of both comparative LCA studies were evaluated with regard to their relevance for environmental beneficial facility management options.

Software All LCAs for the disposable and reusable cups were performed in SimaPro 7.3 (PRé Consultants 2011), but impact results for the disposable cups were imported in Microsoft Excel 2010 for calculating average impact results and spread related to the applied multiple inventory data sets and 
crediting principles for recycling LCAs. Microsoft Excel 2010 was used in both comparative LCA studies for making the appropriate graphical representations of results.

\subsection{Comparison of disposable PS cups and disposable biocups from PLA and biopaper (study 1)}

Van der Harst and Potting (2013) recently made a critical comparison of ten existing LCA studies comparing disposable beverage cups. These ten LCA studies only shared climate change as a common impact category. The variation in climate change results across LCA studies for each disposable cup material was quantitatively explored by Van der Harst and Potting (2013). They calculated the ratio between the highest and lowest climate change value and found a ratio of 1.7 for PLA cups, 3.4 for petro-plastic cups, and 20 for paper cups. Since there was also no consistency among the LCAs about the cup with the smallest climate change impact, Van der Harst and Potting (2013) next qualitatively compared the data used and methodological approach followed in each of the ten LCA studies. Identified possible sources for the variation in outcomes were differences in the properties of the disposable cups (e.g., material choice and weight), differences in the data used, and different choices made in modeling production processes, energy production (e.g., fossil or renewable sources), and waste treatment (e.g., different allocation/crediting principles and waste treatment processes applied).

The critical comparison of the ten LCA studies was the basis for a new in-depth comparative LCA study of disposable cups. Van der Harst and Potting (2014) and Van der Harst et al. (2014) deliberately applied multiple inventory data sets and multiple crediting principles for recycling, a modeling choice, in their LCA study comparing disposable fossil-based PS cups with disposable biobased cups from PLA and biopaper. Their use of multiple inventory data sets and crediting principles for recycling involved the following steps:

1. Initial LCAs with one inventory data set for each process in the life cycle of the disposable cups from the three selected materials (these initial LCAs used incineration as waste treatment process)

2. Contribution and sensitivity analysis to identify processes with major influence on the initial LCA results

3. Collecting additional multiple inventory data sets for all processes with major influence

4. Applying multiple data sets, multiple modelling choices:

- Applying the collected multiple inventory data sets in next LCAs,

- Combined with one waste treatment processes (i.e., incineration, recycling, composting, or anaerobic digestion), and with
- Applying multiple crediting principles for the disposable cup LCAs with recycling (i.e., multiple crediting principles for recycled material)

5. Calculating and presenting average impact results and their spread (highest and lowest value) for each life cycle process based on the multiple inventory data sets and crediting principles for recycling

6. Calculating and presenting average impact results and their spread (highest and lowest value) for each disposable cup

Steps 1 to 6 were gone through for each of the ten disposable cup LCAs. These ten disposable cup LCAs resulted from three disposable materials (i.e., fossil-based PS, biobased PLA and paper lined with PLA), and four waste treatment processes (i.e., incineration, recycling, composting, and anaerobic digestion; the latter two not being relevant for PS). This led to ten disposable cup life cycles for which multiple inventory data sets were collected, whereof three disposable cup life cycles with recycling for which multiple crediting principles were applied (see Table 1). The applied multiple inventory data sets and crediting principles for recycling are related to disposable cups as commonly used in hot beverage vending machines in the Netherlands (i.e., not necessarily for similar disposable cups used abroad). These disposable cups typically have a volume of $180 \mathrm{ml}$ (Dispo International 2012; Huhtamaki 2012b; Krings and Schuh 2012). The difference in the weight of cups made from the same material can vary due to different thickness of the walls. Representative disposable cup weights related to this volume were used in LCA study 1, i.e., $4.2 \mathrm{~g}$ for the PS and PLA ones and $5.6 \mathrm{~g}$ for the biopaper one. See Van der Harst and Potting (2014) and Van der Harst et al. (2014) for relevant ranges in weights.

We only included data sources and sets of good quality and relevant for presently used disposable cups in the Netherlands, e.g., obsolete and/or geographically irrelevant data sets were omitted from the LCA study. See Van der Harst and Potting (2014) and Van der Harst et al. (2014) for specification of data sources and sets used. We also applied multiple crediting principles for recycling, though all grounded in system expansion, e.g., based on recycled PS substituting another material (multiple materials used), or recycled PS replacing virgin PS (multiple value corrections applied). See Van der Harst and Potting (2014) and Van der Harst et al. (2014) for specification of crediting principles and procedures applied.

\subsection{Comparison of disposable PS cups with handwashed and dishwashed reusable cups (study 2)}

The average impact results for the disposable PS cup LCA with incineration from the in-depth LCA study were used for comparison with two reusable cup LCAs, one with handwashing and one with dishwashing of the reusable cup 
Table 1 Overview of the disposable cup materials, cup weight for each material, life cycle processes, and number of inventory data sets and crediting principles included in the in-depth LCA study comparing disposable cups (see Van der Harst and Potting (2014) and Van der Harst et al. (2014) for specification of data sources and sets used and crediting principles and procedures applied). The LCA study covers altogether ten disposable cup life cycles, indicated by the gray-shaded cells, resulting from three disposable cup materials and four waste treatment processes (composting and anaerobic digesting are not relevant for PS). The dark gray-shaded cells indicate the three initial LCAs, each having incineration as waste treatment process. All processes for which only one inventory data set was used, showed to be of minor importance in the contribution and sensitivity analysis

\begin{tabular}{lccc}
\hline Life cycle processes & PS & PLA & Biopaper \\
Representative weights & 4.2 gram & 4.2 gram & 5.6 gram \\
\hline Cradle to disposable cup material production & $\mathbf{3}$ & $\mathbf{5}$ & $\mathbf{5}$ \\
Transport of disposable cup material to cup manufacturer & 1 & $\mathbf{3}$ & 1 \\
Disposable cup manufacturing & $\mathbf{5}$ & $\mathbf{5}$ & $\mathbf{3}$ \\
Cradle to grave for the packaging of disposable cups & 1 & 1 & 1 \\
Transport of disposable cup to customer & 1 & 1 & 1 \\
Transport of used disposable cups to waste treatment & 1 & 1 & 1 \\
Waste treatment: & & & \\
- Incineration & $\mathbf{4}$ & $\mathbf{4}$ & $\mathbf{5}$ \\
- Recycling (recycling process/crediting principle) & $\mathbf{5 / 4}$ & $\mathbf{5 / 4}$ & $\mathbf{3}$ \\
- Composting & & $\mathbf{4}$ & $\mathbf{4}$ \\
- Anaerobic digestion & & $\mathbf{3}$ & $\mathbf{4}$ \\
\hline
\end{tabular}

after use. The comparison took a one-time use of the disposable cup before disposing it, but looked into an increasing number of reuses of the reusable cup before dishwashing or handwashing. No multiple data sets were used in the LCAs for the reusable cup (and since the cups were assumed to be incinerated after use, no crediting principles for recycling was needed). The LCAs for the reusable cup had a screening character, i.e., screening inventory data were used for all processes in the two reusable cup life cycles to calculate the impact results. The weight of the reusable cup was in both LCAs taken to be $370 \mathrm{~g}$, based on a random sample of reusable cups used in the Netherlands. The composition of the reusable cup was taken from Bramberg et al. (2011). The reusable cup was assumed to endure, on average, 1750 consumptions before breaking, and just like the disposable PS cup, sent to the incinerator for waste treatment (Hoeboer 2012).

Dishwashing The composition of the dishwasher was taken from Kok et al. (1996), the energy use for assembling the dishwasher from Boustani et al. (2010), who also gave basis to the assumption of 2150 dishwashing turns before disposing the dishwasher. Waste treatment for the dishwasher was ignored, which is a worst-case approach as large parts of the dishwasher are probably recycled (leading to lower impact results for the dishwasher sub-LCA). Based on currently common dishwashers from AEG and Bosch (Hoeboer 212), the dishwasher was taken to use 9.251 of water, $1 \mathrm{kWh}$ electricity, and $1 \mathrm{~g}$ of salt per washing turn. The composition and use of soap, $9.8 \mathrm{~g}$ per washing turn, was based on Bramberg et al. (2011).

Handwashing Handwashing of the cups was assumed to be a single-item washing (as common for people using an own reusable cup). The use of hot water for handwashing was set on 11 , and the energy use for heating the water was set at $0.22 \mathrm{MJ}$ (based on warming water from 20 to $65^{\circ} \mathrm{C}$ in a boiler with an efficiency of $85 \%$ and using natural gas (Eclectsite 2013)). A use of $1 \mathrm{~g}$ of soap per handwashing was assumed. The soap composition is based on data from the Dutch association of detergent manufacturers (2012). We assumed the use of two paper towels for drying one cleaned cup (Tork 2006; Jacobs 2006). All cradle to product and electricity data in both reusable cup LCAs were taken from the ecoinvent database (EcoInvent Centre 2010).

\section{Results and discussion}

The results of the two LCA studies are presented and discussed according to the four main findings (Sections 3.13.4), followed by a discussion of the meaning of these findings for environmentally beneficial facility arrangements.

\subsection{Disposable PS cups not better or worse than biocups from PLA or biopaper}

Figure 1 shows the full results of the ten disposable cup LCAs for which multiple inventory data sets were used (and multiple crediting principles for the recycling LCAs). These results are qualitatively summarized in Table 2 . The table shows, within each impact category, whether the ratio between average impact results for each of the ten disposable cup LCAs versus the average impact results for the disposable PS cup LCA with incineration is smaller, equal, or larger than one. The other nine disposable cup LCAs consist of one for PS with 


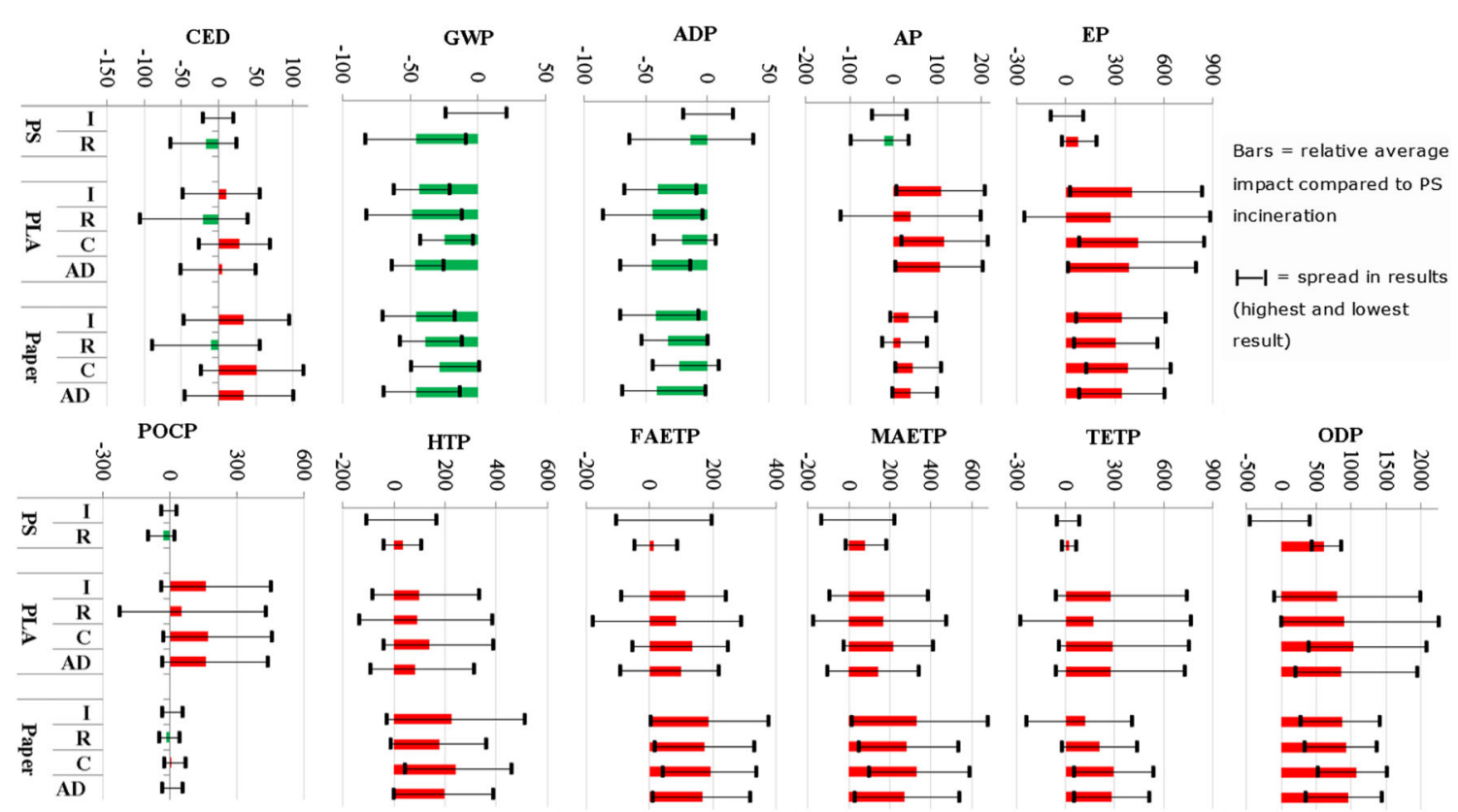

Fig. 1 Comparison of the LCA results of the disposable PS, PLA, and biopaper cups. The bars show the relative impact (in percent) compared to the PS cup with incineration as waste option. A negative value (green) indicates a lower environmental impact than PS incineration, a positive value (red) indicates a higher impact. The spread in impact results reflect the highest and lowest values. $P S$ polystyrene, $P L A$ polylactic acid, $I$ incineration in MSWI, $R$ recycling, $C$ composting, $A D$ anaerobic digestion, $C E D$ cumulated energy demand, $A D P$ abiotic depletion, $G W P$ global warming potential, $A P$ acidification, $E P$ eutrophication, $P O C P$ photochemical oxidation, HTP human toxicity, FAETP freshwater aquatic ecotoxicity, MAETP marine aquatic ecotoxicity, TETP terrestrial ecotoxicity, and $O D P$ ozone layer depletion. This figure is taken from Van der Harst et al. (2014)

in this paper allowed systematic quantification of their influence on the impact results for each of the ten cup LCAs. That is a major achievement of applying multiple inventory data sets and crediting principles for recycling, which in this LCA study, generated a wealth of additional valuable scientific insights. These insight and some additional reflections are summarized here (for more details, see Van der Harst and Potting (2014) and Van der Harst et al. (2014)):

- Only data sources and sets of good quality and relevant for presently used disposable cups in the Netherlands were included in the LCA study of disposable cups. The results from using multiple data sets for inventory analysis are more robust as from using single data sets, because the multiple data sets reflect the existing Dutch market with several active disposable cup manufactures and material producers.

- The large spread in impact results, i.e., from applying multiple inventory data sets and crediting principles for recycling, hampers drawing decisive conclusions about the preferred disposable cup material. This outcome is based on more robust impact results, however, than for those from LCAs based on single inventory data sets per life cycle process

- Despite their large spread, impact results consistently point to the same dominant processes in the LCA results for each disposable cup material. These dominant 
Table 2 Comparison within each impact category of average impact results for all disposable cup LCAs versus the average impact results for the disposable PS cup LCAs with incineration. Impact results for each of the other nine life cycles are higher than ( $>$, darker gray shading), lower than $(<$, lighter gray shading) or similar as $(1$, similar gray shading) the average results of the disposable PS cups that is incinerated after use. The waste treatment processes used in the LCAs are indicated by I = incineration, $\mathrm{R}=$ recycling, $\mathrm{C}=$ composting, $\mathrm{D}=$ anaerobic digestion

\begin{tabular}{|c|c|c|c|c|c|c|c|c|c|c|}
\hline \multirow[t]{2}{*}{ Impact category indicators } & \multicolumn{2}{|c|}{ PS } & \multicolumn{4}{|c|}{ PLA } & \multicolumn{4}{|c|}{ Biopaper } \\
\hline & I & $\mathrm{R}$ & I & $\mathrm{R}$ & $\mathrm{C}$ & $\mathrm{D}$ & I & $\mathrm{R}$ & $\mathrm{C}$ & $\mathrm{D}$ \\
\hline Abiotic Depletion Potential (ADP) & 1 & $<$ & $<$ & $<$ & $<$ & $<$ & $<$ & $<$ & $<$ & $<$ \\
\hline Cumulative Energy Demand (CED) & 1 & $<$ & $>$ & $<$ & $>$ & $>$ & $>$ & $<$ & $>$ & $>$ \\
\hline Global Warming Potential (GWP) & 1 & $<$ & $<$ & $<$ & $<$ & $<$ & $<$ & $<$ & $<$ & $<$ \\
\hline Stratospheric Ozone Depletion Potential (ODP) & 1 & $>$ & $>$ & $>$ & $>$ & $>$ & $>$ & $>$ & $>$ & $>$ \\
\hline Acidification Potential (AP) & 1 & $<$ & $>$ & $>$ & $>$ & $>$ & $>$ & $>$ & $>$ & $>$ \\
\hline Eutrophication Potential (EP) & 1 & $>$ & $>$ & $>$ & $>$ & $>$ & $>$ & $>$ & $>$ & $>$ \\
\hline ground-level PhotoChemical Oxidation Potential (PCOP) & 1 & $<$ & $>$ & $>$ & $>$ & $>$ & $<$ & $<$ & 1 & $<$ \\
\hline Human Toxicity Potential (HTP) & 1 & $>$ & $>$ & $>$ & $>$ & $>$ & $>$ & $>$ & $>$ & $>$ \\
\hline Terrestrial EcoToxicity Potenital (TETP) & 1 & $>$ & $>$ & $>$ & $>$ & $>$ & $>$ & $>$ & $>$ & $>$ \\
\hline Fresh-water Aquatic EcoToxicity Potential (FAETP) & 1 & $>$ & $>$ & $>$ & $>$ & $>$ & $>$ & $>$ & $>$ & $>$ \\
\hline Marine aquatic EcoToxicity Potential (MAETP) & 1 & $>$ & $>$ & $>$ & $>$ & $>$ & $>$ & $>$ & $>$ & $>$ \\
\hline
\end{tabular}

processes turned out to be the same as identified in the contribution analysis (i.e., none of the used inventory data sets made a given process into a minor contributor in the impact results for the cup LCAs)

- Particularly, cradle to PLA production dominated the impact results for the four PLA cup LCAs. It should be noted that PLA production was based on "cold" PLA. The technology for thermo-resistant PLA used in the PLA cups was not yet available at the time of our LCA. Consequently, data on the production of this thermoresistant PLA were not obtainable then. Disposable PA cups are still not widely used, and to our knowledge, also not yet commercially produced.

- Production of all three disposable cup materials can environmentally improve, but this potential is probably largest for the relative new material PLA that is presently produced from economically valuable sugar and starch. PLA can also be made from lignocellulosic biomass (Shen et al. 2009). PLA production instead from lignocellulosic waste residues in arable crops farming may yield environmental merits, as no extra land and fertilizers are needed. Whether this will lead to net environmental gains, however, will, among others, depend on the extra efforts needed to free useful sugars locked in by lignin, hemicellulose, and cellulose.

- The crediting of recycled material also considerably influenced the impact results for the recycling LCAs across all three disposable cup materials

- Across disposable cup materials, spread in impact results for energy-related impact categories tend to be clearly smaller than in non-energy-related impact categories (in the toxicity categories particularly)

- Average impact results for abiotic depletion and global warming are better for the disposable biocups than for
PS cups, because PLA and paper are made from renewable materials and PS is made from fossil fuels

- Correlations between inventory data within one data set, e.g., between energy use and carbon dioxide emissions, are maintained by calculating spread on the basis of impact result. Mainstream LCA studies first calculate spread in inventory data, before performing impact assessment, which often violates existing correlations between inventory data within one data set.

\subsection{Recycling slightly preferable over incinerating disposable cups}

Table 3 shows the ranking of cup LCAs, within one disposable cup material, according to the average impact results for the used waste treatment process. Disposable cups of one material were ranked only within each impact category, and the ranking is thus not relevant for comparing across impact categories. Within one disposable cup material, the spread in impact results is identical from cradle to waste treatment, which allows focusing on the waste treatment processes only. There is also a large, but only partly overlapping spread in average impact results for the waste treatment processes within each disposable cup material (see Van der Harst and Potting 2014; Van der Harst et al. 2014). Some cautious preferences are possible to express on the basis of average results for the waste treatment process (i.e., not necessarily supported by the range in impact results for these processes).

For both disposable biocups, composting is less good than the other three waste treatment processes in all impact categories as a result of the absence of useful products derived from composting (e.g., both disposable biocups do not contain nutrients). Composting therefore does not get credits, in contrast 
Table 3 Ranking within each impact category according to average impact results of waste treatment processes within disposable cup materials (no weighting across impact categories was performed)

\begin{tabular}{|c|c|c|c|c|c|c|c|c|c|c|}
\hline \multirow[t]{2}{*}{ Impact categories } & \multicolumn{2}{|c|}{ PS } & \multicolumn{4}{|c|}{ PLA } & \multicolumn{4}{|c|}{ Biopaper } \\
\hline & I & $\mathrm{R}$ & $\mathrm{I}$ & $\mathrm{R}$ & $\mathrm{C}$ & $\mathrm{D}$ & I & $\mathrm{R}$ & $\mathrm{C}$ & $\mathrm{D}$ \\
\hline Abiotic Depletion Potential (ADP) & 2 & 1 & 3 & 1 & 4 & 1 & 1 & 3 & 4 & 2 \\
\hline Cumulative Energy Demand (CED) & 2 & 1 & 3 & 1 & 4 & 2 & 2 & 1 & 4 & 2 \\
\hline Global Warming Potential (GWP) & 2 & 1 & 3 & 1 & 4 & 2 & 1 & 3 & 4 & 1 \\
\hline Stratospheric Ozone Depletion Potential (ODP) & 1 & 2 & 1 & 3 & 4 & 2 & 1 & 2 & 4 & 3 \\
\hline Acidification Potential (AP) & 2 & 1 & 3 & 1 & 4 & 2 & 2 & 1 & 4 & 3 \\
\hline Eutrophication Potential (EP) & 1 & 2 & 3 & 1 & 4 & 2 & 3 & 1 & 4 & 2 \\
\hline Ground-level PhotoChemical Oxidation Potential (PCOP) & 2 & 1 & 3 & 1 & 4 & 2 & 2 & 1 & 4 & 3 \\
\hline Human Toxicity Potential (HTP) & 1 & 2 & 3 & 2 & 4 & 1 & 3 & 1 & 4 & 2 \\
\hline Terrestrial EcoToxicity Potenital (TETP) & 1 & 2 & 2 & 1 & 4 & 2 & 1 & 2 & 4 & 3 \\
\hline Fresh-water Aquatic EcoToxicity Potential (FAEP) & 1 & 2 & 3 & 1 & 4 & 2 & 3 & 2 & 4 & 1 \\
\hline Marine Aquatic EcoToxicity Potential (MAEP) & 1 & 2 & 3 & 2 & 4 & 1 & 3 & 2 & 3 & 1 \\
\hline
\end{tabular}

Lowest impact results are indicated by 1 , highest impact results are indicated by 4

$I$ incineration, $R$ recycling, $C$ composting, $D$ anaerobic digestion

to the other three waste treatment processes, for the avoided production of replaced products, including energy. For the PLA cup, anaerobic digestion performs on average within all except two impact categories slightly better than incineration for the PLA cup (i.e., avoided impact by energy production from biogas is larger than from incineration with energy recovery). It should be noted that data for anaerobic digestion of PLA are from lab tests and theoretical calculations, and also based on cold PLA rather than on thermo-resistant PLA. There is no similar trend for the biopaper cup. The ranking of average impact results within each cup material in Table 3 suggest a preference of recycling over incineration for the PLA cup and a slight preference for recycling over incineration for the biopaper cup. The avoided impact of recycling is better than incineration in 8 out of 11 impact categories for the disposable PLA cup, and in 5 out of 11 impact categories for the disposable biopaper cup. For the disposable PS cups, the average impact results are better in 5 and worse in 6 impact categories for recycling as compared to incineration. The comparison of recycling and incineration, however, revealed an interesting methodological issue of system expansion (i.e., crediting processes with avoided production caused by their co-products).

The disposable cup LCAs with incineration as waste treatment process got relative large credits for avoided electricity production from energy recovery by incineration, and these credits for incineration became more dominant when inventory data for improved disposable cup material production were used (i.e., credits for recycling became less). This suggests incineration to become preferable when disposable cup material production improves, but this needs some reflections:
Dutch policies aim to considerably improve the environmental performance of Dutch energy supply, among others by increasing the share of renewables (Government of the Netherlands 2014). Compared to other countries, Dutch electricity production presently uses little renewable sources, and predominantly relies on "dirty" fossil fuels (CBS 2012; European Commission 2012; Eurostat 2012). Most relevant renewable sources for the Netherlands are biomass, wind, and solar. However, the ecoinvent database did not contain a readymade scenario for this. We therefore performed a sensitivity analysis with hydro-dominated Norwegian electricity instead of Dutch electricity production. This showed better impact results in more impact categories for recycling than for incineration of disposable PS cups.

There are also methodological issues at stake in the comparison of recycled and incinerated cups. One relates somewhat to the sensitivity analysis with hydro-dominated Norwegian electricity production because it can be discussed if average electricity production in the Netherlands is the correct technology for system expansion in the LCAs for the incinerated cups (see e.g., Finnveden and Ekval 1998; Merrild et al. 2008). It could be argued that e.g., "clean" electricity production should have been used for system expansion. Another methodological issue relates to a potential bias from comparing two life cycles where crediting co-benefits in the one case can be (partly) solved within the product life cycle (i.e., subtracting production of virgin material according to the amount replaced by recycled material), and in the other case needs to be solved by extension with a process outside the initial life cycle (e.g., electricity production for incineration with energy recovery). This methodological issue of 
(semi-)closed versus open loop system expansion needs in our opinion further research.

The relatively large credits for avoided Dutch electricity production affected the comparison of cup LCAs with incineration and recycling as waste treatment process for all three disposable cup materials, but this particularly shows for the disposable PS cup in Table 3. On the basis of our LCA results and considering the Dutch energy objectives, we therefore conclude a cautious preference for recycling over incinerating disposable cups. Other reflections worth to be mentioned here (Potting 2013; Potting and van der Harst 2014):

- Pilot experiments suggest that efficiency and contamination of separate collection of disposable cups depends on the way of collecting (e.g., in stacks or loose in bins or containers). Contamination of the collected disposable cups was roughly $40 \%, 20 \%$ of beverage-remainders, and $20 \%$ others (e.g., plastic stirrer, plastic bread bags, metal staples, clock houses, etc.)

- PLA is not compostable in a back-garden compost heap, but disposable PLA and biopaper cups both compost well in (semi-)industrial compost facilities. This was confirmed by composting experiments under semiindustrial composting conditions we performed as part of the Wageningen UR project. Cold instead of thermoresistant disposable cups were used in these experiments. The experiments showed visible traces of incomplete composted PLA from the cups, which make the compost unfit for commercial sales

- Disposable biocups are, in practice, hardly composted in Dutch commercial composting facilities as compostable and non-degradable cups are difficult to distinguish.

\subsection{Dishwashing not convincing better than handwashing for reusable cups}

Figure 2 shows the impact results of the screening LCAs of the reusable cup LCAs. The impact results are expressed as ratio with the average impact results for the disposable PS cup LCA with incineration (which is used for one hot beverage consumption only). The reusable cups were compared within each impact category only and thus not across impact categories. The reusable cup LCA with dishwashing performs slightly better than the reusable cup LCA with handwashing on most impact categories. The impact results for handwashing particularly are strongly influenced, however, by the userdependent amount of hot water, soap, and paper towels applied in the screening LCA. These amounts were set on reasonable worst-case amounts, but may in practice be considerably higher as well as lower. The user-dependent load efficiency of the dishwasher is one of the influences in the other reusable cup LCA. It is thus difficult to express a preference for either dishwashing or handwashing of reusable cups on the basis of these results.

As can also be seen from Fig. 2, the impact results for both reusable cups roughly halves with two hot beverage consumptions before washing. The environmental gain declines with every next consumption before washing, however, and more than two or three consumptions does hardly lead anymore to a decrease of impact results. The disposable cups can, of course, also be used for more than one consumption, and then a similar decline is at stake for them with every next consumption before disposing.

\subsection{Reusable cups not better or worse than disposable PS}

The impact results for the reusable cup LCAs, which had a screening character (e.g., only single inventory data sets for all life cycle processes), have been compared with the average impact results for the in-depth disposable PS cup LCA with incineration (which is used for one hot beverage consumption only). The reusable cups and disposable PS cups were compared within each impact category only, and thus not across impact categories.

Similar to reusable cups, disposable cups can also be used for more than one consumption before disposing them. A fair comparison therefore should be based on using reusable and disposable cups for the same number of consumptions. This number of consumptions can be any, as long as it is similar between reusable and disposable cups. Based on one consumption for both reusable and disposable cup, see Fig. 2, the impact results for the reusable cup LCAs with dishwashing are better in seven and worse in four impact categories compared to the disposable PS cup. The impact results for the reusable cup LCA with handwashing are worse than the impact results for the disposable PS cup LCA in all impact categories. As already mentioned in Section 3.3, however, the impact results for the reusable cup LCA with handwashing are strongly influenced by the user-dependent amounts of hot water, soap, and paper towels applied in the screening LCA (which represent reasonable worst-case amounts). The impact results for the two reusable cups LCAs are thus uncertain, whereas there is a large spread in results for the disposable PS cup LCA (see Section 3.1 and Fig. 1). This makes it impossible to express a preference for one of the reusable or disposable PS cups.

\subsection{Facility arrangements improving the environmental performance of all cups}

All cup comparisons in this paper are performed within impact categories only and not across impact categories. The overall comparison does not allow any preference for one of the three disposable cup materials and neither for disposable versus reusable cups from an environmental point of view. This gives 


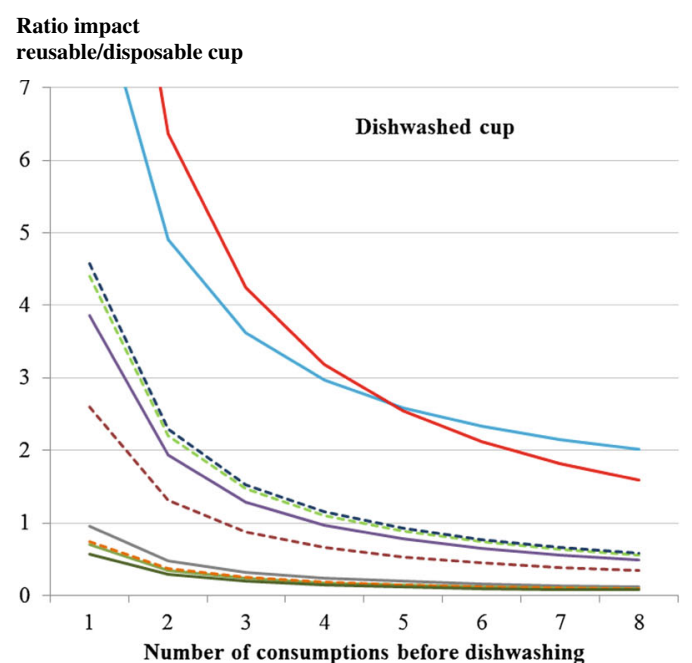

Fig. 2 Impact results for the reusable cup LCAs, with dishwashing on the left and with handwashing on the right, expressed as ratio of the average impact results for the disposable PS cup LCA with incineration as waste

facility managers a certain freedom to choose for the cup complying with the facility arrangement best fitting in their organization. Some organizations may prefer a reusable cup, e.g., because it has a more luxurious image. Other organizations are perhaps bound to disposable cups due to peak consumptions or the absence of cleaning facilities. Some organizations may prefer disposable biopaper cups for their environmentally friendly image, while other organizations may prefer disposable PS cups because they are cheaper than disposable (bio)paper cups. Disposable (bio)paper cups also tend to disrupt vending machines with automatic cup supply (Heuvelmans and Ploum 2010). Some organizations therefore would like to stick to disposable PS cups, whereas others may want to change to disposable PLA cups. Disposable PLA cups for hot beverages, i.e., from thermo-resistant PLA, are not yet used on a wide scale and, to our knowledge, also not yet commercially produced. The technology for producing them has recently become available (Wageningen UR 2012), but the commercial production of these disposable PLA cups is locked in a clumsy impasse. The cup producer is waiting for sufficiently large demand to make the production economically viable, while potential clients are waiting for the disposable PLA cups to become available on the market (Potting 2013). Disposable PLA cups for cold beverages are already longer on the market (Huhtamaki 2012a).

It is regularly said that consumers only want to be "green" as long as they do not have to pay more. That may or may not be true in general, but was contradicted by several organizations approaching us during the Wageningen UR project that encompassed the LCA studies in this paper. The organizations were interested in making the transition to disposable PLA cups despite their expected substantial higher price and also despite the fact that they are presently not better (nor worse) than disposable PS cups. One argument put forward several
Ratio impact

reusable/disposable cup

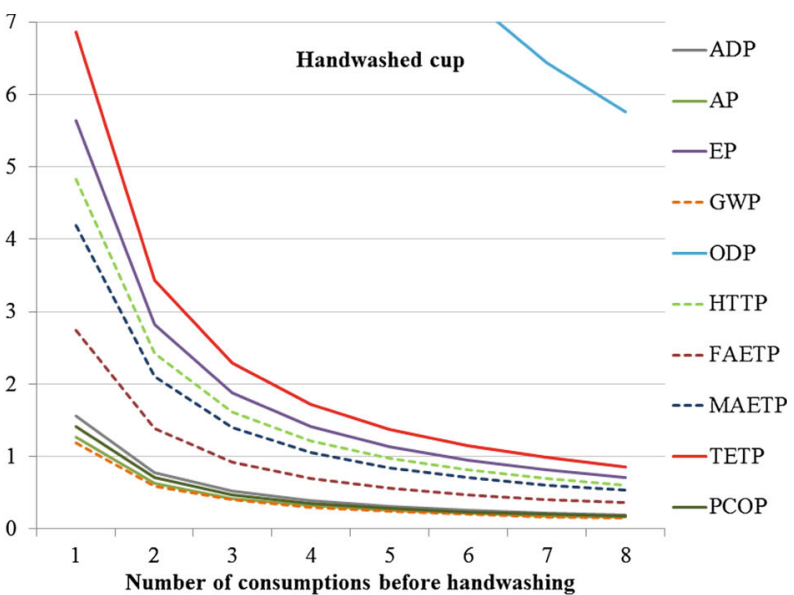

treatment. The disposable PS cups here are taken to be used for one hot beverage consumption only. An increasing number of uses before washing is evaluated for the reusable cup

times was the wish to give a boost to further development and environmental improvement of the disposable PLA cup (i.e., PLA production). As mentioned in Section 3.1, there is probably a larger improvement potential for PLA then for PS or biopaper production.

While the overall comparison does not allow a preference for any disposable cup materials or for using a handwashed or dishwashed reusable cup, Fig. 2 do indicate for the reusable cups a considerable environmental gain from a second and possibly third hot beverage consumption before washing it. This environmental gain obviously also exist for increasing the number of consumptions of the disposable cup before throwing it away. A second or third consumption is roughly the number of hot beverages that a consumer takes during one morning or one afternoon. Since pathogens probably do not multiply so fast and consumers usually do not share cups, there seems no real public health issue here. Facility managers can encourage a second or third serving with the same cup by financial incentives (e.g., paying for a new disposable cup), only putting on the dishwasher around noon and after working time, and/or consumer awareness activities.

Disposable cups from PLA and biopaper are often advertised with their compostability as selling point. Disposable biocups are, in practice, not composted in Dutch commercial composting facilities, however, since compostable and nondegradable cups are difficult to distinguish. Commercial composting also does not allow complete composting of PLA cups, i.e., their turnaround time is less than the required composting time of the cups, which leads to visible traces in the compost. Composting disposable biocups also performs less good than the other three waste treatment options. Recycling disposable cups tend to perform slightly better than incineration of disposable cups, if the bias of the relative large credits for avoided dirty Dutch electricity production in the 
incineration LCAs is taken into account. Separate collection and recycling of disposed cups may environmentally optimize facility arrangement using disposable cups.

Wageningen UR recently (partly) made the transition of replacing conventional disposable PS cups by disposable biopaper cups in their office buildings that have vending machines for hot beverages without automatic cup supply. The new lease contract for the hot beverage vending machines includes the supply of disposable biopaper cups next to the vending machine, and also a system for separate collection and recycling of the disposed biopaper cups. Information on the vending machines and on the disposable biopaper cups stimulates their reuse. The education buildings of Wageningen UR still have hot beverage vending machines with automatic supply of disposable PS cups. These vending machines do not supply a new cup, however, if another cup is placed under the outlet. The reuse of disposable PS cups is stimulated by extra charging the supply of a new cup on top of the price for the hot beverage. It would be interesting to learn whether those facility measures will (substantially) reduce the use of disposable cups by Wageningen UR. Wageningen UR used 2.5 million disposable cups in 2010 (Potting 2013).

\section{Conclusions}

All comparisons in this paper are within each impact category only and not across impact categories. The overall results do not allow any preference for one of the three disposable cup materials (large and overlapping spread in impact results), and neither for disposable versus reusable cups (impact results for the latter are too uncertain and too close to those for the disposable cups). All cups can be used more than once, however, before getting rid of a disposable cup or washing a reusable cup. This gives a considerable environmental gain for the second and third hot beverage consumption with the reusable as well as disposable cups. Facility managers can encourage a second or third serving with the same cup by financial incentives (e.g., paying for a new disposable cup), only putting on the dishwasher around noon and after working time, and/or consumer awareness activities.

It was not possible to indicate a preference for one of the three disposable cups, but comparison of waste treatment processes for each cup material justified to express some cautious preferences on the basis of average impact results. Composting is the least preferred waste treatment for both biocups. Anaerobic digestion performs better than incineration for the disposable PLA cup in most impact categories, though this trend does not apply for the biopaper cup. The average impact results suggest in most impact categories a (slight) preference of recycling over incineration for the PLA cup and biopaper cup, i.e., the impact of recycling is smaller than for incineration, but not for the PS cups which average impact results are better in five and worse in six impact categories for recycling as compared to incineration. The comparison of recycling and incineration, however, is biased by the relative large credits for avoided dirty Dutch electricity production. Against this background, there is a slight preference for recycling for all three disposable cup materials.

The in-depth LCA study comparing the disposable cups deliberately applied multiple inventory data sets for the processes contributing most to the impact results as well as multiple crediting principles for recycling. This led to a large spread in impact results, though for energy related impact categories smaller than for the others. The large spread in impact results may be less easy to interpret, but they represent more robust results.

Acknowledgments This paper has been made possible by funding of the Province of Gelderland in the Netherlands. Additional financial support has been provided through the VINNMER-program from Vinnova Swedish Governmental Agency for Innovation Systems. The comparison between disposable PS and reusable cups elaborated from the BSc thesis of Robert Hoeboer who was at that time a student at Wageningen University. The feedback of two anonymous reviewers was instrumental in improving the quality of this paper. Hereby, we like to express our thanks to everybody who has contributed to this paper.

Open Access This article is distributed under the terms of the Creative Commons Attribution 4.0 International License (http:// creativecommons.org/licenses/by/4.0/), which permits unrestricted use, distribution, and reproduction in any medium, provided you give appropriate credit to the original author(s) and the source, provide a link to the Creative Commons license, and indicate if changes were made.

\section{References}

Boustani A, Sahni S, Gutowski T, Graves S (2010) Appliance remanufacturing and energy savings. Sloan School of Management, Cambridge

Bramberg G, Rasmanis V, Westerdahl M, Karlberg C (2011) A comparative LCA of ceramic cups and disposal paper cups. KTH Royal Institute of Technology, Stockholm

CBS (2012) Renewable energy in the Netherlands 2010. Statistics Netherlands, The Hague/Heerlen

Dispo International (2012) Vending cups. http://www.dispo.co.uk/ products.html. Retrieved on 1 Mar 2012

Dutch association of detergent manufacturers (2012) Detergent for handwashing dishes. http://www.isditproductveilig.nl/was_en reinigingsmiddelen/pages/view.php?page_id $=69$. Retrieved 15 Jun 2012

Eclectsite (2013) http://www.eclecticsite.be/calc/waterVerwarmen.htm. Retrieved 28 May 2013

Ecoinvent Centre (2010) Ecoinvent data v. 2.2. Final reports Ecoinvent Dübendorf (Switzerland)

European Commission (2012) Energy. Country factsheets. 2012.V.1.3

Eurostat (2012) Electricity production and supply statistics. http://epp. eurostat.ec.europa.eu/statistics explained/index.php/Electricity production and supply statistics. Retrieved on 21 Apr 2014

Finnveden G, Ekval T (1998) Life-cycle assessment as a decision-support tool-the case of recycling versus incineration of paper. Resour Conserv Recycl 24(3-4):235-256 
Franklin Associates (2006) Life Cycle Inventory of five products produced from polylactide (PLA) and petroleum-based resins. Technical report. Eastern Research Group, Inc

Franklin Associates (2009) Life cycle inventory of 16-ounce disposable hot cups. Final peer-reviewed report. Eastern Research Group, Inc

Franklin Associates (2011) Life cycle inventory of foam polystyrene, paper-based, and PLA foodservice products. Eastern Research Group, Inc., Prairie Village

Frischknecht R, Jungbluth N, Althaus H-J, Doka G, Dones R, Hellweg S, Hischier R, Humbert S, Margni M, Nemecek T, Spielmann M (2003) Implementation of life cycle impact assessment methods. Final reports Ecoinvent 2000 No. 3: Dübendorf, Switzerland

Government of the Netherlands (2014) More renewable energy in the future (Meer duurzame energie in de toekomst). http://www. rijksoverheid.nl/onderwerpen/duurzame-energie/meer-duurzameenergie-in-de-toekomst. Retrieved 4 Nov 2014

Guinée JB, Gorrée M, Heijungs R, Huppes G, Kleijn R, de Koning A, van Oers L, Wegener Sleeswijk A, Suh S, Udo de Haes HA, de Bruijn H, van Duin R, Huijbregts MAJ (2002) Handbook on life cycle assessment. Operational guide to the ISO Standards. Kluwer Academic Publishers, Dordrecht

Häkkinen T, Vares S (2010) Environmental impacts of disposable cups with special focus on the effect of material choices and end of life. J Clean Prod 18:1458-1463

Heuvelmans K, Ploum L (2010) Implementation research biocups. Research into the introduction of disposable cups from renewable and compostable materials at Wageningen UR. Wageningen University, Wageningen (the Netherlands). Internal report, in Dutch, not published

Hoeboer R (2012) How user behaviour can change the environmental impacts of an earthenware coffee mug. An LCA. Wageningen University, Wageningen (the Netherlands). Internal report, in Dutch, not published

Huhtamaki (2012a) Bioware. Cold drink cups. http://www.foodservice. huhtamaki.co.uk/products/product_type/root/category?categoryId= 29\&rootId=55\&nodeId=28. Retrieved on $22 \mathrm{Mar} 2012$

Huhtamaki (2012b) Vending \& water. http://www.foodservice. huhtamaki.co.uk/products/product_sector/root/?nodeId= 23\&rootId=267. Retrieved 1 Mar 2012

ISO (2006) ISO 14044 International Standard. In: Environmental management-life cycle assessment-requirements and guidelines. International Organization for Standardization (ISO), Geneva

Jacobs (2006) Pulp and paper industry energy bandwidth study. American Institute of Chemical Engineers, New York

Jager LC (2008) Consumers appreciate biological degradable packaging (in Dutch). BioKnowledge News (BioKennis nieuws)

Kok R, Benders RMJ, Moll HC (1996) EAP-analyses of the Dutch consumption spending in 1996. Addendem of the report Energy intensities of the Dutch consumption spending in 1996 (in Dutch). IVEM, University of Groningen, Groningen, the Netherlands

Krings, Schuh OHG (2012) Automatenbecher. http://www.plastikbecher. de/index.php?lang=deu\&list=automatenbecher. Retrieved 1 Mar 2012

Ligthart TN, Ansems AMM (2007) Single use cups or reusable (coffee) drinking systems: an environmental comparison. TNO, Apeldoorn

Merrild H, Damgaard A, Christensen TH (2008) Life cycle assessment of waste paper management: the importance of technology data and system boundaries in assessing recycling and incineration. Resour Conserv Recycl 52:1391-1398
NatureWorks LLC (2011) Sourcing Ingeo: raw materials. http://www. natureworksllc.com/The-Ingeo-Journey/Raw-Materials. Retrieved on $13 \mathrm{Feb} 2011$

PE Americas (2009) Comparative life cycle assessment Ingeo biopolymer, PET and PP drinking cups. For Starbucks Coffee Company Seattle, WA \& NatureWorks LLC. Joint venture of Five Winds and $\mathrm{PE}$ International

Pladerer C, Meissner M, Dinkel F, Zschokke M, Dehoust G, Schüler D (2008) Comparative life cycle assessment of various cup systems for the selling of drinks at events, p 137. Österreichisches ÖkologieInstitut (Austrian Institute of Ecology), Carbotech AG and ÖkoInstitut e.V. Deutschland (German Institute of Ecology). Vienna, Basel, Darmstadt

Potting J (2013) A biocup of coffee (biobakkie koffie)? Wageningen University, Wageningen

Potting J, van der Harst E (2014) Facility arrangements, food safety, and the environmental performance of disposable and reusable cups. Proceedings of the 9th International Conference LCA of Food, 810 October 2014, San Francisco, USA

PRé Consultants (2011) SimaPro, Amersfoort, the Netherlands

Reinink M, Oosterkamp I, Savelkouls X (1991) No future for disposables? Research into the use of disposable plastic cups and packaging materials at Wageningen University (Report nr. 55; in Dutch). Sociology of Consumers and Households, Wageningen University, Wageningen, the Netherlands

Shen L, Haufe J, Patel MK (2009) Product overview and market projection of emerging bio-based plastics. PRO-BIP 2009. Utrecht University: Copernicus Institute for Sustainable Development and Innovation, Utrecht, p 243

Tork (2006) Tork premium hand towel interfold Soft. http://www.tork.nl/ product/100288. Retrieved 15 Jun 2012

Uihlein A, Ehrenberger S, Schebek L (2008) Utilisation options of renewable resources: a life cycle assessment of selected products. J Clean Prod 16:1306-1320

Van der Harst E, Potting J (2013) A critical comparison of ten disposable cup LCAs. Environ Impact Assess Rev 43:86-96

Van der Harst E, Potting J (2014) Variation in LCA results for disposable polystyrene beverage cups due to multiple data sets and modelling choices. Environ Model Softw 51:123-135

Van der Harst E, Potting J, Kroeze C (2014) Multiple data sets and modelling choices in a comparative LCA of disposable beverage cups. Sci Total Environ 494-495:129-143

Vercalsteren A, Spirinckx C, Geerkens T, Claeys P (2006) Comparative LCA of 4 types of drinking cups at events, OVAM, Public Waste Agency for the Flemish Region

Von Blottnitz H, Curran MA (2007) A review of assessments conducted on bioethanol as a transportation fuel from a net energy, greenhouse gas and life cycle perspective. J Clean Prod 15:607-619

Wageningen UR (2012) Biocups for hot coffee now possible. http:// resource.wageningenur.nl/en/show/Biocups-for-hot-coffee-nowpossible.htm. Retrieved 9 Jul 2012

Weiss M, Haufe J, Carus M, Brandão M, Bringezu S, Hermann B, Patell M (2012) A review of the environmental impacts of biobased materials. J Ind Ecol 16(S1):169-181

Wikiversity (2014) Design for the environment/disposable coffee cups. http://en.wikiversity.org/wiki/Design_for the Environment/ Disposable_Coffee_Cups. Retrieved 16 Apr 2014 